\title{
Update on the use of topical calcineurin inhibitors in cutaneous lupus erythematosus
}

\author{
This article was published in the following Dove Press journal: \\ Biologics:Targets \& Therapy \\ I I February 20I I \\ Number of times this article has been viewed
}

\section{Michael Sticherling \\ Hautklinik, Universitätsklinikum Erlangen (Clinic of Dermatology, University Hospitals of Erlangen), Erlangen, Germany}

Correspondence: Michael Sticherling Hautklinik, Universitätsklinikum Erlangen, Hartmannstr. I4, D-9I052

Erlangen, Germany

$\mathrm{Tel}+49$ 9|3| 853385|

$\mathrm{Fax}+49$ 913। 8536185

Email michael.sticherling@uk-erlangen.de

\begin{abstract}
Cutaneous manifestations of lupus erythematosus (CLE) are manifold, presenting with unspecific skin manifestations or well-defined clinical dermatological entities. Their relation to each other as well as to systemic lupus erythematosus is variable, yet diagnostically and therapeutically challenging. Therapeutic decisions have to be based on the activity and distribution as well as the type of skin lesions and the extent of systemic disease. Limited skin manifestations may be amply tackled by topical therapy, so far, mainly relying on corticosteroids. In many cases, however, internal treatment has to be combined by using antimalarials, in addition to strict UV-protection. The advent of topical calcineurin inhibitors has contributed substantially to the armamentarium of external treatment options. By specifically interfering with intracytoplasmic signal transduction to activate the nuclear factor of activated T-cells (NF-AT), they are able to modulate various inflammatory mechanisms. The two available compounds, pimecrolimus and tacrolimus, do not induce the skin atrophy characteristic of corticosteroids. They have been studied in a number of case reports, but only in a few randomized, comparative studies. Both are well-tolerated, but differentially effective in the various subsets of CLE. Further studies are needed to directly compare the two compounds to each other, as well as to topical corticosteroids, before final recommendations can be made.
\end{abstract}

Keywords: cutaneous lupus erythematosus, calcineurin inhibitors, topical therapy, systemic therapy

\section{Introduction}

Cutaneous manifestations within lupus erythematosus (LE) are manifold and their relation to systemic disease and its course and prognosis is often debated. Systemic lupus erythematosus (SLE) may present with skin symptoms either as the first clinical manifestation or during the further course of the disease in up to $70 \%$ of cases. However, dermatology has defined distinct clinical subsets of cutaneous LE (CLE), which may solely affect the skin or may eventually develop into systemic disease. ${ }^{1-4}$ In contrast to SLE as a chronic inflammatory multiorgan disease with variable clinical appearance and course, the cutaneous subsets only show mild internal involvement (eg, mild arthralgia and malaise). ${ }^{5}$ However, at first diagnosis and during the further course of the disease, systemic manifestation and organ involvement have to be carefully excluded to allow appropriate treatment. ${ }^{6}$ In addition, cutaneous side effects of any drug treatment have to be carefully separated from disease-related manifestations.

The current classification of cutaneous lesions is still based on the initial observation by Gilliam in $1977,{ }^{7}$ who defined non-specific and specific skin manifestations. ${ }^{8}$ Non-specific lesions comprise vascular lesions such as the syndrome of Raynaud, 
thrombophlebitis, and periungual teleangiectases..$^{5,9}$ Furthermore, different clinical manifestations of cutaneous vasculitis are typical of such non-specific features such as leukocytoclastic vasculitis, livedo racemosa, and hypocomplementemic urticarial vasculitis. In addition, diffuse or mottled alopecia with telogen effluvium during disease flares-ups, erythema multiforme, or calcinosis cutis can be found. Whereas non-specific lesions are common in SLE, they may also be seen in association with specific cutaneous lesions.

Specific CLE lesions can be allocated and classified to distinct subtypes ${ }^{3}$ that may be variably interpreted by dermatologists and rheumatologists. Lesions are specified according to clinical, immunoserological, and histological parameters, into acute cutaneous lupus erythematosus (ACLE), subacute cutaneous lupus erythematosus (SCLE), chronic cutaneous lupus erythematosus (CCLE) and intermittent cutaneous lupus erythematosus (ICLE).

ACLE may present as the classical, centrofacially-located butterfly rash in its localized form or as a generalized maculopapular exanthema. ${ }^{5}$ Typically, patients are severely ill due to the underlying SLE and demonstrate diverse organ manifestations as well as anti-dsDNA antibodies.

In contrast to ACLE as a cutaneous manifestation of SLE, SCLE is sometimes interpreted as the borderline between strictly-limited dermal and systemic disease. Two clinically different forms are seen and present as a polycyclic anular eczema-like variant, and an erythemato-papulosquamous (psoriasiform) variant. Due to distinct ultraviolet light (UV) sensitivity, lesions are mainly found on sun-exposed areas like the forearms, the upper body, and neck, in a symmetrical distribution. Although the characteristic presence of anti-Ro/ SSA and anti-La/SSB autoantibodies indicates systemic disease, clinically, only mild arthralgia or myalgia are found in some cases. On the other hand, patients may fulfil up to 4 criteria defined by the American College of Rheumatology for SLE.

Apart from UV light, various drugs have been described as inducers of SCLE, including terbinafine and angiotensinconverting enzyme inhibitors..$^{10,11}$

CCLE can be classified as discoid LE (DLE), LE profundus (LEP) and chilblain LE (CHLE). In contrast to the other forms discussed so far, CCLE may result in distinct skin atrophia and scarring, which dictate early diagnosis and treatment to prevent permanent, disfiguring disease.

DLE is the most common form of CCLE, and of CLE as a whole group. It presents with well-demarcated erythematosquamous plaques and characteristic pain when touched (the so-called "carpet tack sign"). Most lesions are located on the face and the scalp (localized form), but can also involve the lips or the oral mucosa, where sharply demarcated plaques and ulcers with irregular borders might mimic oral lichen planus.

As DLE may occur in $20 \%$ of patients with SLE, systemic disease has to be excluded, even more so in cases of disseminated manifestation (20\%) of DLE, and in those $5 \%$ of patients who show distinctly positive antinuclear antibodies (ANA).

LEP afflicts $1 \%-3 \%$ of all CLE patients. ${ }^{12,13}$ The characteristic tender subcutaneous nodular infiltrations are located in the deep dermis and subcutaneous fat of the proximal extremities, the buttock and the head as well as trunk. They are referred to as LE panniculitis, and in cases with overlying discoid lesions, as LE profundus. However, both terms are often used interchangeably. Characteristically, lesions resolve with deep lipathrophia and scarring. Older lesions may even calcificate. Although up to $75 \%$ of patients show positive ANA titers (but no specific autoantibodies), the clinical manifestation of additional SLE is rare. ${ }^{1}$

CHLE is predominantly located at the nose and ears as well as at the distal extremities, especially the fingers and toes, with livid, red-to-purple nodules and plaques. ${ }^{5,14,15}$ As CHLE presents in response to cold temperatures and humidity, it is often clinically and histologically difficult to differentiate from perniones. Although elevated ANA, anti-Ro, or positive rheumatoid factors are rarely found, ${ }^{14}$ SLE may occur in about $20 \%$ of patients.

ICLE, or lupus erythematosus tumidus (LET), has only recently been allocated to CLE in a modified classification introducing an intermittent cutaneous LE. ${ }^{3,16}$ In contrast to the other CLE variants discussed so far, this very rare variant of LE lacks significant epidermal manifestations and scarring or atrophy. ${ }^{16}$ As the disease is eminently UV-sensitive, the characteristic erythematous urticarial papules and plaques are found in an anular or centrifugal presentation on the face, the upper proximal extremities, and the chest or trunk. The course and prognosis of ICLE are very good, and an association with SLE uncommon. although elevated ANA levels are detectable in about $10 \%-30 \%$, and anti-Ro or anti-La autoantibodies in about $5 \%$ of patients.

\section{Pathogenesis}

The pathogenesis of CLE, especially differential traits for the various subsets described above, is still unknown in detail, as is the varying relation to SLE. ${ }^{17}$ Various genetic and immunogenetic factors were shown to contribute 
to CLE, but without giving distinct clues to differential effects. ${ }^{17}$ In addition, various environmental factors were identified, such as drugs, ${ }^{10}$ infections, and UV light, as contributing to the clinical manifestation of CLE, among other factors, and to explain its seasonal accumulation. ${ }^{18,19}$ Within this context, the effects of UV light have been studied most extensively. An increased number of apoptotic cells has been found either in skin biopsies from diseased skin or after experimental UV irradiation. ${ }^{20-22}$ This accumulation may either result from an increased induction or delayed clearing of apoptotic cells. During these processes, autoimmune phenomena may be induced by increased accessibility of DNA, or Ro/La antigens, due to their expression on the cell membranes of apoptotic cells. In addition, a pro-inflammatory environment was shown in CLE lesions, with an increased expression of different cytokines such as interferons and TNF-(tumor necrosis factor) alpha, as well as a shift in T-cell immunity. Most recently, $\mathrm{CD}^{+}, \mathrm{CD} 25^{+}$, and regulatory T-cells $\left(\mathrm{T}_{\text {reg }}\right)$ were extensively studied. LE patients were shown to inappropriately suppress other T-cell populations and their proliferation in cutaneous lesions. ${ }^{17}$

These pathogenic traits result in characteristic histomorphologic changes. All CLE manifestation, apart from LET, will show a more or less distinct interface dermatitis and basal cell necrosis with thickening of the basement membrane and a mononuclear periadnexial infiltrate. Whereas these features may be discrete in SCLE, hyperkeratosis and epidermal atrophy are prominent in DLE. Lobular panniculitis with dense infiltrates of lymphocytes and plasma cells, and deposition of mucin between the adipocytes, are characteristic of LEP. Increased dermal deposition of mucin and inflammation of the superficial periadnexal and perivascular areas are characteristic of LET.

Thus, anti-inflammatory and immunomodulatory strategies seem most promising in the treatment of LE. Regarding the scarring propensity of CLE at most visible sites, an early and effective treatment is required.

\section{Diagnostic procedures}

As outlined above, the various subsets of CLE are variably related to SLE, either at the time of first diagnosis or during further disease progress. Therefore, careful examinations have to be performed to exclude any internal involvement, which apart from the joints, may affect important organs like the lungs, heart, kidneys, and the central nervous system. ${ }^{6}$ Any further diagnostic examinations must rely on a careful case history and clinical examination, which will dictate histopathologic and laboratory tests, as well as technical examinations.

Basic laboratory screening will include a complete blood cell count, liver and renal function tests, acute phase proteins, and urinanalysis, whereas specific laboratory examinations comprise inflammatory, autoimmune and infectious disease parameters. ${ }^{6}$

If clinical- or laboratory-identified dysfunctions of internal organs are found, additional specific technical investigations related to lung, heart, and brain involvement are necessary, on an individual basis.

The special impacts of dermatology on the diagnostics of CLE are with histological and immunohistological examinations, as well as the diagnostic testing of UV-sensitivity. ${ }^{5,21}$ Although the so-called lupus band test has lost most of its clinical significance, due to the availability of more sensitive anti-dsDNA tests, it may still be reasonably performed together with a histological examination of diseased skin (see above). ${ }^{23}$ Altogether, a final diagnosis may often be possible only by adding and balancing clinical, immunoserological, and histological features.

UV-sensitivity and provocation tests are hardly necessary for final diagnosis, but will help evaluate the individual impact of photosensitivity, and thus increase the patient's awareness of a correlation between UV exposure and skin lesion. ${ }^{6,21}$ Thus, compliance to adequate UV protection and treatment recommendations will be increased.

\section{Treatment}

Regarding therapeutic studies available on CLE, three major drawbacks must be considered. First, the different subsets of CLE have hardly been discriminated; too often, studies only refer to CLE as a group or, even worse, only to "skin symptoms". Secondly, if CLE subsets are differentiated, different criteria for diagnosis of CLE subsets have been used that furthermore, have changed over time. Thirdly, activity criteria that have been defined and amply evaluated hereto are hardly available, resulting in yet another severe obstacle to direct comparison between different clinical studies. ${ }^{24}$ In 2005, a new disease index score, the cutaneous lupus erythematosus disease area and severity index (CLASI), was described for the evaluation of cutaneous lesions. ${ }^{25}$ In this score, "activity" is separated from "damage". The CLASI score for activity decreases after successful therapy, whereas the damage score may increase in scarring forms of CLE. Therefore, this score correlates with the improvement of global skin health, pain, and itch, and is a useful tool to measure clinical responses to different treatments. ${ }^{26}$ Alternatively, 
activity scores, such as the systemic lupus activity measure (SLAM), or the systemic lupus erythematosus disease activity index (SLEDAI) are available. ${ }^{24}$ However, they evaluate laboratory parameters and organ involvements that are not very representative of CLE. Recently, a standardized set of clinical core data has been suggested by the European Society for Cutaneous LE. ${ }^{27}$

Early diagnosis and treatment are mandatory for CLE, especially in cases with scarring disease, to prevent any residual and irreversible disfiguration. Furthermore, the risk of neoplastic transformation in long-standing hypertrophic and scarring disease has to be minimized. The choice of treatment will further rely on the disease subset of CLE, the extent of skin disease, as well as the presence and extent of internal organ involvement. ${ }^{6,28-30}$ Disease manifestations that are restricted to the skin only, and in a limited distribution, may amply be tackled with topical treatment, whereas refractory or rapidly-progressing disease needs systemic therapy. Systemic corticosteroids are of limited effect in CLE and may be used in the initial phase of treatment, while highly inflammatory lesions are present, in doses well above $0.5 \mathrm{mg} / \mathrm{kg}$ body weight. Regarding the systemic side-effects of corticosteroids, immunosuppressive or immunomodulatory drugs need to be added for their adjuvant effect. ${ }^{31}$ The mainstays of systemic treatment for more severe cases of CLE are antimalarials, mainly hydroxychloroquine and chloroquine. ${ }^{32-34}$ Alternatives are dapsone, for more inflammatory lesions, ${ }^{35}$ and retinoids for distinctly hyperkeratotic lesions, as well as methotrexate. ${ }^{36}$ The antimetabolites azathioprine, mycophenolate mofetil, ${ }^{37-39}$ and leflunomide show delayed and only inferior responses. ${ }^{6}$

\section{Topical treatment options}

Protection against UV light is recommended for all types of CLE. This can be achieved by textiles (eg, sun hat, long-sleeved clothes), as well as additional physical and chemical sunscreens with sun protection filters for UVA and UVB well above factor 25. Patients with CLE should not work in professions or pursue leisure activities related to high UV exposure, and should not travel to Mediterranean and tropical countries without ample sun protection.

Especially in patients with scarring CLE or acute inflammatory lesions, additional make-up or camouflage may be psychologically helpful. ${ }^{40}$

The manifestations of all subsets of CLE can be improved by the topical application of corticosteroids, but to a varying extent. ${ }^{6,28}$ Initial treatment should be performed once-daily with medium-strength topical corticosteroids such as prednicarbate or methylprednisolone-aceponate (eg, for the face). At sites apart from the face, more potent corticosteroids such as mometasonfuroat or betamethasone can be tried. An intralesional or occlusive application of potent corticosteroids might be indicated in distinctly hyperkeratotic lesions. Alternatively, in these cases the topical application of retinoids might be useful.

Any surgical or invasive procedures, such as tunable dye laser, dermabrasion, or excision should only be performed in individual cases of stable or, preferably, extinct disease lesions because of the possible Koebner phenomenon. ${ }^{19}$

\section{Calcineurin inhibitors}

With regard to the prominent unwanted effects of corticosteroids, especially with their long-term or repetitive use, alternative topical treatments are much needed. These have evolved with the advent of compounds that belong to the group of macrolactames, and are called calcineurin inhibitors by their mode of action, which seems to rely primarily on the decrease or blocking of cytokine production by activated T-lymphocytes. ${ }^{41-43}$ The therapeutic exploitation of calcineurin inhibition is well-established with ciclosporin, a cyclic peptide derived from a Scandinavian mold. ${ }^{42}$ It is licensed as a systemic agent to prevent the rejection of transplanted solid organs, as well as for the treatment of severe atopic eczema and psoriasis. Its clinical efficacy as a topical agent for skin diseases is, however, limited. Recently, 2 novel calcineurin inhibitors, tacrolimus and pimecrolimus, became available for topical application. ${ }^{44-47}$ They are currently licensed and well-established for the treatment of moderate to severe atopic dermatitis, due to their prominent immunomodulatory effects. ${ }^{46,48-50}$ Over the past years, a variety of clinically and pathogenically different inflammatory skin diseases have been reported to respond to topical calcineurin inhibitors, among them, various subsets of CLE. These reports cover single or few cases to date. However, placebo-controlled, double blind studies, and comparative, head-to-head studies of both substances are hardly available.

\section{Calcineurin inhibitors: mode of action}

Both of the available topical calcineurin inhibitors are purified from bacteria and further processed. Tacrolimus, or FK 506, was first described, as early as 1984, as a product of soil bacteria found at Mount Tsukuba in Japan. It shows close similarity 
to other macrolide antibiotics. ${ }^{45-48}$ Thus, its name was coined from "Tsukuba macrolide immunosuppression". In contrast, pimcrolimus was produced from Streptomyces hygroscopicus as a semi-synthetic derivate of ascomycin. ${ }^{44,51}$

The main targets of both compounds are T-lymphocytes, apart from eosinophilic and basophilic granulocytes, as well as mast cells, with an inhibition of their cytokine synthesis and release. Whereas the number of Langerhans cells in the epidermis remains unchanged, some of their functional parameters are modulated. ${ }^{52-54}$ In contrast, keratinocytes, fibroblasts, and endothelial cells are spared. This is in clear contrast to the pleiotropic effects of corticosteroids, which non-selectively modulate both the number and function of various cell subsets.

The immunomodulatory effects of tacrolimus and pimecrolimus were investigated in vitro and found to result from binding to the intracytoplasmic protein makrophilin-12, which in turn inhibits calcineurin. This serine-threonine phosphatase plays an important role in activating the nuclear transcription factor NFkB, which binds to the promotor regions of various cytokines, such as intereukin (IL)-2, TNF- $\alpha$, interferon- $\gamma$, IL-4 and IL-10. The (indirect) inhibition of NFKB by calcineurin inhibitors will thus result in a decrease of these cytokines.

Whereas the functional activities of both substances are similar, their different chemical structures result in different lipophilia and penetration into the skin. Pimecrolimus, being more lipophilic, shows a higher epidermal affinity, but lower penetration into the skin, and lower resorption. In vivo inflammatory models demonstrated a high anti-inflammatory, but comparatively very low immunosuppressive activity. As no skin atrophy is observed, calcineurin inhibitors may be used at sensitive skin areas including the face, neck, and intertriginous areas. ${ }^{55,56}$ Interestingly, no increase of bacterial or viral infection was found in clinical studies, which underlines the beneficial characteristics of the compounds. Both are licensed for children above the age of 2 years for the treatment of moderate to severe atopic eczema. The only major side-effects are burning, erythema, and irritation, which are mostly reversible and transient. No significant systemic resorption, ${ }^{57}$ accumulation, or systemic side effects are found, nor allergic, photosensitizing, or phototoxic properties. Though the photocarcinogenic activity, based on earlier studies, was minimal, the US Federal Drug Agency in 2005 imposed a black box warning on the longterm use of both compounds, in recognition of the limited clinical data and the possible risk of skin malignancies. ${ }^{50,58}$

\section{Calcineurin inhibitors for CLE}

Tacrolimus is available as $0.03 \%$ and $0.1 \%$ ointments and pimecrolimus as $1 \%$ cream. Small studies, mostly open-label, and case reports have been published for all 3 preparations, but mainly for $0.1 \%$ tacrolimus in the treatment of DLE. Only 3 studies compared effects to a topical corticosteroid, and none to placebo. Two double-blind, placebo-controlled studies on pimecrolimus are available, one of these only as an abstract.

Recently, a number of reviews have summarized the use of calcineurin inhibitors in dermatology, covering the licensed use for atopic dermatitis as well as off-licence applications in psoriasis, lichen planus, pyoderma gangrenosum, and cutaneous lupus erythematosus. ${ }^{41,43,59}$

Walker et $\mathrm{a}^{60}$ treated two female patients with recalcitrant DLE with a combination of $0.05 \%$ clobetasole propionate and $0.3 \%$ tacrolimus twice daily. After 6 and 8 weeks respectively, almost complete resolution of the facial manifestation could be observed. No side-effects were reported.

In a case series, Yoshimasu et $\mathrm{al}^{61}$ evaluated 11 patients (3 SLE, 4 DLE, 4 dermatomyositis) who applied $0.1 \%$ tacrolimus once daily. 6 patients (3 SLE, 1 DLE, 2 dermatomyositis) showed a marked regression of their skin lesions. However, 4 patients (3 DLE, 1 dermatomyositis) were resistant to the therapy. In contrast to the lack of improvement in DLE, a good response was observed for facial erythematous lesions with edematous or telangiectatic changes in systemic LE and dermatomyositis. No adverse effects were induced by tacrolimus.

Böhm et $\mathrm{al}^{62}$ published a study of three patients with facial lesions of LE, one with systemic LE and a malar rash, one with annular subacute cutaneous LE, and another with a papular variant of subacute cutaneous LE. After adjunct treatment with either $0.03 \%$ or $0.1 \%$ tacrolimus ointment for 5 to 8 weeks, all patients experienced significant improvement. All patients received various systemic drugs at the same time, including antimalarials and systemic corticosteroids. In all patients, tacrolimus ointment was well-tolerated, except for transient pruritus and burning in one patient. No measurable peripheral blood levels of tacrolimus could be found in a representative laboratory test in one patient.

Bacman et al ${ }^{63}$ treated 1 patient with LET using tacrolimus $0.1 \%$ ointment on one side of the face, compared to methylprednisolone on the other side, with good clinical response and tolerability after 4 weeks, and complete clearing upon prolonged application. No reference is made, however, to the course of the skin disease after stopping the topical treatment. 
Table I List of clinical studies on topical calcineurin inhibitors for CLE

\begin{tabular}{|c|c|c|c|c|}
\hline Drug compound & CLE subtype & Protocol & Study type & Reference \\
\hline $\begin{array}{l}\text { Tacrolimus } 0.3 \% \\
\text { combined with } \\
\text { clobethasol } 0.05 \%\end{array}$ & DLE & 6-8 weeks twice daily & case report & Walker et $\mathrm{al}^{60}$ \\
\hline Tacrolimus $0.1 \%$ & SLE, DLE & 4 weeks once daily & case report & Yoshimasu et al ${ }^{61}$ \\
\hline $\begin{array}{l}\text { Tacrolimus } 0.1 \% \text { or } \\
0.03 \%\end{array}$ & SLE, SCLE & $\begin{array}{l}5-8 \text { weeks once or } \\
\text { twice daily }\end{array}$ & case report & Böhm et $\mathrm{al}^{62}$ \\
\hline Tacrolimus $0.1 \%$ & LET & 4 weeks twice daily & case report & Bacman et $\mathrm{al}^{63}$ \\
\hline Tacrolimus $0.1 \%$ & SLE & 4 weeks twice daily & case report & Kanekura et al ${ }^{64}$ \\
\hline Tacrolimus $0.1 \%$ & DLE & 8 weeks twice daily & case report & $\begin{array}{l}\text { de la Rosa Carillo and } \\
\text { Christensen }\end{array}$ \\
\hline Tacrolimus $0.1 \%$ & SCLE & 8 weeks twice daily & case report & Drüke et $a^{66}$ \\
\hline Tacrolimus $0.1 \%$ & SLE, SCLE, DLE & $>6$ weeks twice daily & open label study & Lampropoulos et al ${ }^{67}$ \\
\hline Tacrolimus $0.1 \%$ & SCLE & 3 weeks twice daily & case report & Meller et $\mathrm{al}^{68}$ \\
\hline Tacrolimus $0.1 \%$ & DLE & 12 weeks twice daily & open label study & Heffernan et a ${ }^{69}$ \\
\hline Tacrolimus $0.1 \%$ & DLE & 4-8 weeks twice daily & case report & Sugano et $\mathrm{a}^{70}$ \\
\hline Tacrolimus $0.1 \%$ & SLE, DLE & $\begin{array}{l}3 \text { weeks twice daily } \\
\text { 4-week follow-up }\end{array}$ & case report & von Pelchrzim et al ${ }^{71}$ \\
\hline $\begin{array}{l}\text { Tacrolimus } 0.1 \% \text { vs } 0.05 \% \\
\text { clobetasol proprionate }\end{array}$ & SLE, SCLE, DLE & 4 weeks twice daily & $\begin{array}{l}\text { randomized double blind } \\
\text { bilateral comparison }\end{array}$ & Tzung et $\mathrm{al}^{72}$ \\
\hline Tacrolimus $0.03 \%$ & SCLE & 6 weeks & case report & Cooper et $\mathrm{al}^{73}$ \\
\hline $\begin{array}{l}\text { Tacrolimus } 0.3 \% / 0.005 \\
\text { clobetasol vs.tacrolimus } 0.1 \%\end{array}$ & DLE, SCLE, SLE & twice daily & retrospective study & Madan et al. ${ }^{74}$ \\
\hline Tacrolimus $0.03 \%$ & linear DLE & one year & case report & Kawachi et al. ${ }^{75}$ \\
\hline Tacrolimus $0.1 \%$ & DLE & 8 weeks twice daily & case report & Han et al. ${ }^{76}$ \\
\hline Pimecrolimus I\% cream & DLE & 8 weeks twice daily & case report & Han et al. ${ }^{76}$ \\
\hline Pimecrolimus I\% cream & & not given & case report & Zabawski $^{77}$ \\
\hline Pimecrolimus I\% cream & $\begin{array}{l}\text { SLE, SCLE } \\
\text { DLE, LET }\end{array}$ & $\begin{array}{l}3 \text { weeks twice daily } \\
\text { 8-week follow-up }\end{array}$ & open label study & Kreuter et $\mathrm{al}^{78}$ \\
\hline Pimecrolimus I\% cream & DLE & 8 weeks twice daily & open label study & Tlacuilo-Parra et al ${ }^{79}$ \\
\hline $\begin{array}{l}\text { Pimecrolimus I\% cream } \\
\text { vs placebo }\end{array}$ & SCLE, DLE & $\begin{array}{l}4 \text { weeks twice daily } \\
4 \text {-week follow-up }\end{array}$ & $\begin{array}{l}\text { randomized double blind, } \\
\text { placebo controlled, bilateral } \\
\text { comparison }\end{array}$ & Sticherling et a $\left.\right|^{80}$ \\
\hline $\begin{array}{l}\text { Pimecrolimus } 1 \% \text { cream } \\
\text { vs } 0.1 \% \text { betamethasone }\end{array}$ & DLE & 8 weeks twice daily & randomized double blind & Barikbin et $\mathrm{a}^{81}$ \\
\hline
\end{tabular}

Kanekura et a ${ }^{64}$ treated 3 SLE patients with malar rash using topical $0.1 \%$ tacrolimus ointment twice-daily for 3 weeks on one half of the face, and compared the response to the untreated side. After 3 weeks, erythema on the treated side improved in all 3 patients. No burning sensation, skin-tingling, irritation, or pruritus at the site of application of the ointment was reported.

De la Rosa Carrillo and Christensen ${ }^{65}$ reported a female patient with long-standing DLE of her face and scalp who was treated with tacrolimus $0.1 \%$ ointment. Interestingly, apart from clearing of facial lesions, regrowth of terminal hair on most of the scalp was observed. No side-effects were reported.

Drüke et $\mathrm{a}^{66}$ studied a 51-year-old female patient with SLCE who was treated with $0.1 \%$ tacrolimus twice-daily. Almost complete resolution was found after an 8-week treatment, which persisted to a 3-month follow-up. The only complaint of the patient was a slight burning pain at the beginning of the treatment.
Lampropoulos et a ${ }^{67}$ studied 12 patients with recalcitrant CLE, 6 of them with DLE, 4 with SCLE, and 2 with SLE using $0.1 \%$ tacrolimus ointment for a minimum of 6 weeks. The clinical response was evaluated by patients' and physicians' assessments and documented with clinical photographs at baseline and at the end of the treatment. One patient stopped the treatment due to unwanted local effects such as burning and peeling. Six of the other 11 patients improved distinctly. One patient showed minor improvement of his facial lesions, while 4 patients remained unchanged. Within the 3 clinical subsets included, only 2 of the 4 patients with SCLE showed significant regression of their lesions, while the other 2 remained unchanged. Two of the 6 DLE patients showed "certain" improvement (1 with only minor improvement, and 3 with no response at all). On the other hand, significant improvement of their skin rashes was found in the 2 SLE patients. 
Meller et a ${ }^{68}$ studied an 83-year-old female patient with SCLE on the upper extremities and upper trunk, which improved after a 3 -week treatment twice-daily with $0.1 \%$ tacrolimus ointment. The authors judged the compound to be an effective and safe alternative to the established topical treatment of CLE. No side-effects were reported.

Heffernan et al ${ }^{69}$ conducted an open-label pilot study including 5 patients with DLE who were treated with $0.1 \%$ tacrolimus ointment twice daily for 12 weeks. Two target lesions were monitored every 4 weeks, assessing their size (diameter), erythema, scarring, and thickness on a 5-point scale. Only 3 patients completed the study, with mild, moderate, and marked improvements, respectively, and apparently no side-effects. This study included only a low number of patients, without a control group, using a non-validated skin score.

Sugano et al ${ }^{70}$ studied 4 Japanese patients with DLE who were successfully treated with topical tacrolimus ointment $(0.1 \%)$ twice daily. The erythematous plaques diminished distinctly after $4-8$ weeks. No local adverse effects were observed.

Von Pelchrzim et al ${ }^{71}$ observed variable responses of facial lesions but absence of adverse events in 4 patients suffering from SLE and DLE when treated with topical tacrolimus $0.1 \%$ ointment for up to 2 months. Two patients (1 with SLE and 1 with DLE) showed marked regression of their skin lesions after 3 weeks of treatment, whereas the others showed no response.

Tzung et al ${ }^{72}$ conducted a randomized, double-blind study comparing the efficacy and safety of $0.1 \%$ tacrolimus ointment and $0.05 \%$ clobetasol propionate ointment in the treatment of facial CLE. 20 patients (13 with malar rash of SLE, 4 with DLE, and 1 with SCLE) applied $0.1 \%$ tacrolimus ointment to the affected areas on one side of the face and $0.05 \%$ clobetasol propionate ointment to the other side of the face. Skin lesions were assessed at each visit (weeks $0,1,2,3,4$, and post-treatment week 4) using a 7-point rating scale that included erythema, desquamation, and induration. To improve the penetration of the compound into the skin, a standardized microdermabrasion was performed after each assessment, once-weekly. Of the enrolled 20 patients, 11 women and 7 men completed the study. There was no significant difference between tacrolimus and clobetasol. All lesions worsened at week 8 (ie, 4 weeks after stopping the treatment), although they were still better than at baseline. However, 11 patients (61\%) developed telangiectasia on the clobetasol side of the face as early as week 3 . This study clearly shows similar effects of tacrolimus and clobetasol, yet distinct differences in side-effects. The clinical effects are restricted to the time of treatment, with slow deterioration after stopping the therapy.

Cooper et $\mathrm{al}^{73}$ studied for 2 months a 6-month-old girl with SCLE born to a mother with Sjögren syndrome. Her facial lesions resolved completely with application of $0.03 \%$ tacrolimus ointment for 6 weeks.

Madan et al. ${ }^{74}$ recently published a retrospective study on the topical treatment with tacrolimus $0.3 \%$ in fixed combination with clobetasolepropionat $0.05 \%$ twice daily in therapy resistant CLE. Eleven of 13 patients with CLE (DLE n=11, SCLE $\mathrm{n}=1$, SLE $\mathrm{n}=1$ ) showed a good to excellent response compared to 5 patients who were treated with $0,1 \%$ tacrolimus without corticosteroid. The rationale of this study is not evident as the higher efficacy of tacrolimus $(0.3 \%)$ plus clobetasole compared to monotherapy with tacrolimus $(0.1 \%)$ is all but surprising. The concentration of $0.3 \%$ has neither been evaluated nor licensed. In addition, the study comprises a low number of patients.

Two most recent publications reported on the successful administration of calcineurin inhibitors in DLE. Kawachi et al. ${ }^{75}$ treated the rare case of a six year old Japanese girl with linear DLE following the lines of Blaschko. Clinical improvement was seen after prolonged treatement with topical tacrolimus $0.03 \%$ over one year. Similarly, Han et al. ${ }^{76}$ treated four patients with DLE successfully and with good tolerability using either tacrolimus $0.1 \%$ or pimecrolimus twice daily for 8 weeks.

The number of case reports and studies on pimecrolimus is much lower than for tacrolimus. Some are discussed below.

Zabawski ${ }^{77}$ was the first to describe a single patient with facial plaques of discoid lupus erythematosus, who was treated with pimecrolimus $1 \%$ cream, resulting in moderate improvement. However, the treatment protocol, the duration of treatment, adverse events, and method of assessing the improvement are not mentioned.

Kreuter et $\mathrm{al}^{78}$ presented data from 11 patients with different forms of cutaneous lupus erythematosus (4 DLE, 2 SCLE, 3 SLE, 2 LET) who were treated in an open, uncontrolled study with pimecrolimus $1 \%$ cream under semiocclusive conditions twice-daily for 3 weeks. Skin involvement was assessed before and after therapy by means of a clinical score. A significant regression of skin lesions by $52 \%$ was observed after therapy in all patients, and the improvement of skin status was sustained in most of the patients during a follow-up period of 8 weeks. In contrast to long-standing and distinctly hyperkeratotic DLE, early 
erythematous lesions of SCLE and LE tumidus showed a better response. Minimal transient burning was observed in only one case, at the beginning of treatment.

Tlacuilo-Parra et al $^{79}$ conducted an open-label, phase II trial on 10 patients with discoid lupus who were treated with pimecrolimus $1 \%$ cream twice-daily for 8 weeks. They assessed skin involvement with a clinical severity score, quality of life, patient improvement, and toxicity. Furthermore, clinical changes were documented by skin biopsy at baseline and at the end of treatment. In all patients, a 56\% improvement in the clinical severity score for skin damage was observed after therapy, as well as a $46 \%$ improvement in the quality of life score. $50 \%$ of the patients qualified their skin improvement as marked, $40 \%$ as moderate and $10 \%$ as slight. The treatment was well-tolerated, apart from short-term minimal erythema and pruritus.

Sticherling et $\mathrm{al}^{80}$ conducted a double-blind, placebocontrolled study of 25 patients with CLE (13 DLE, 12 SCLE), using a twice-daily application of $1 \%$ pimecrolimus cream or placebo for 4 weeks. The local tolerance was very good, and similar in both groups. In both groups, the skin score comprising erythema, infiltration, scaling, and diameter of lesions decreased from 5.5 before treatment to 2.8 after treatment. No differences of efficacy were found upon stratification of DLE and SCLE. The amount of cream used in either group was identical, excluding a possible bias. During the 4-week, blinded follow-up period, the skin score increased to 3.4 in both groups.

Most recently, Barikbin et $\mathrm{al}^{81}$ conducted a randomized, double-blind pilot study of ten patients with facial lesions of DLE, comparing topical pimecrolimus $1 \%$ cream and topical betamethasone 17 -valerate $0.1 \%$ cream twice daily for 8 weeks. Using a combined score based on the evaluation of erythema, infiltration, and presence of scales, a distinct, however not statistically significant, improvement was found in both groups, with a decrease of $86 \%$ and $73 \%$ respectively for pimecrolimus and betamethasone. This study contained a low number of patients and is in clear contrast to other reports on rather poor responses of DLE.

Altogether 144 patients have been studied, in 23 case reports or studies, who were treated with either pimecrolimus ( $n=59$ in 6 publications) or tacrolimus ( $n=85$ in 17 publications). There are 15 case reports, with varying numbers of patients all but one using tacrolimus, and 4 studies in either open-label ( 2 each on pimecrolimus and tacrolimus) or randomized, double-blind $(\mathrm{n}=3)$ settings. The latter 3 compared 2 agents, either in bilateral fashion or within separate treatment arms. Two studies used both agents on either side of the face, one study comparing $0.1 \%$ tacrolimus ointment to $0.05 \%$ clobetasol propionate in combination with microdermabrasion once weekly, ${ }^{72}$ another comparing $1 \%$ pimecrolimus to placebo. ${ }^{80}$ The third study compared $1 \%$ pimecrolimus to betamethasone 17 -valerate $0.1 \%$ cream in 2 separate treatment groups. ${ }^{81}$ Regarding the different clinical subsets of CLE, 9 reports on 37 patients examined DLE only (4 using tacrolimus, 3 using pimecrolimus), and only 3 case reports covered SCLE. All other publications comprised at least 2 of the clinical CLE subsets. The respective clinical definitions and activity scoring have been grossly divergent, making a direct comparison of the studies very difficult. Furthermore, prior or concomittent treatment has been varying.

\section{Conclusion}

In summary, both of the available topical calcineurin inhibitors are generally well tolerated, but effective to a varying extent in the diverse CLE subsets. Whereas cutaneous lesions of SLE generally respond well, only slight effects are demonstrated for SCLE. For DLE, the results are less convincing because distinct hyperkeratosis will result in a low penetration of the compounds.

A number of general reviews have addressed the use of calcineurin inhibitors in dermatology beyond atopic dermatitis and positively judged their effects on cutaneous autoimmune diseases including CLE. At the same time, all authors demand further clinical studies. ${ }^{82-88}$

Due to the lack of comparative data, no clear-cut reference can be made to the differential effectiveness of either reagent. Monotherapy in highly active and disseminated cases does not seem promising, especially not in DLE, whereas SCLE and SLE skin lesions seem to respond better. In more severe and recalcitrant cases, combined systemic treatment with antimalarials is advised. Apart from these, more general conclusions and recommendations, no evidence-based, evaluated protocols for the use of calcineurin inhibitors in CLE are available but may be deduced from their effective clinical use in atopic eczema. ${ }^{46,89}$ Here, the initial treatment of highly inflammatory lesions with topical corticosteroids is followed by topical calcineurin inhibitors. A chronic, long-term treatment is licenced for mildly inflammatory or prodromal lesions with an alternative treatment every other day or weekend-only treatment as an alternative.

The fear of a UV-related increase in skin tumors seems overrated for CLE, as the patients are advised to strictly adhere to UV protection. ${ }^{90}$

Consequently, with the advent of topical calcineurin inhibitors, an interesting treatment alternative to corticosteroids 
became available. They are, at most, comparable to topical corticosteroids but with fewer unwanted effects. However, before final decisions and recommendations on their use for CLE are made, multicenter studies, with clearly defined classification and activity criteria, on a sufficient number of individuals are needed, which directly compare the two calcineurin inhitors to either placebo, topical corticosteroids, and/or to each other.

\section{Disclosure}

This work is not supported by any funding sources and has not been previously presented. The author does not have a conflict of interest to disclose within the last two years.

\section{References}

1. Costner MI, Sontheimer RD, Provost TT. Lupus erythematosus. In: Sontheimer RD, Provost TT, eds. Cutaneous Manifestations of Rheumatic Diseases. Philadephia: Williams \& Wilkins; 2003: 15-64.

2. Rothfield N, Sontheimer RD, Bernstein M. Lupus erythematosus: systemic and cutaneous manifestations. Clin Dermatol. 2006;24: 348-362.

3. Kuhn A, Ruzicka T. Classification of cutaneous lupus erythematosus. In: Kuhn A, Lehmann P, Ruzicka T, editors. Cutaneous Lupus Erythematosus. Heidelberg: Springer; 2004:53-58.

4. Tebbe B, Orfanos CE. Prognosis of cutaneous lupus erythematosus. In: Kuhn A, Lehmann P, Ruzicka T, editors. Cutaneous lupus erythematosus. Heidelberg: Springer; 2004. p. 187-204.

5. Renner R, Sticherling M. The different faces of cutaneous lupus erythematosus. G Ital Dermatol Venereol. 2009;144:135-147

6. Sticherling M, Bonsmann G, Kuhn A. Diagnostic approach and treatment of cutaneous lupus erythematosus. J Deutsch Dermatol Ges. 2008;6:48-61.

7. Gilliam JN. The cutaneous signs of lupus erythematosus. Cont Educ Fam Phys. 1977;6:37-40.

8. Gilliam JN, Sontheimer RD. Distinctive cutaneous subsets in the spectrum of lupus erythematosus. J Am Acad Dermatol. 1981;4: $471-475$.

9. Provost TT. Nonspecific cutaneous manifestations of systemic lupus erythematosus. In: Kuhn A, Lehmann P, Ruzicka T, editors. Cutaneous lupus erythematosus. Heidelberg: Springer; 2004:93-106.

10. Vasoo S. Drug-induced lupus: an update. Lupus. 2006;15:757-761.

11. Sontheimer RD, Henderson CL, Grau RH. Drug-induced subacute cutaneous lupus erythematosus: a paradigm for bedside-to-bench patient-oriented translational clinical investigation. Arch Dermatol Res. 2009;301:65-70.

12. Massone C, Kodama K, Salmhofer W, et al. Lupus erythemtaosus panniculitis (lupus profundus): clinical, histopathological and molecular analysis of nine cases. J Cutan Pathol. 2005;32:396-404.

13. Requena L, Sanchez YE. Panniculitis (Part II). Mostly lobular panniculitis. J Am Acad Dermatol. 2001;45:325-361.

14. Kuhn A, Sticherling M, Bonsmann G. Clinical manifestations of cutaneous lupus erythematosus. J Deutsch Dermatol Ges. 2007;5: 1124-1140.

15. Lee-Kirsch MA, Gong M, Schulz H, et al. Familial chilblain lupus, a monogenic form of cutaneous lupus erythematosus, maps to chromosome 3p. Am J Hum Genet. 2006;79:731-737.

16. Ruiz H, Sanchez JL. Tumid lupus erythematosus. Am J Dermatopathol. 1999;21:356-360.

17. Kuhn A, Bijl M. Pathogenesis of cutaneous lupus erythematosus. Lupus. 2008;17:389-393.
18. Mond CB, Peterson MG, Rothfield NF. Correlation of anti-Ro antibody with photosensitivity rash in systemic lupus erythematosus patients. Arthritis Rheum. 1989;32:202-204.

19. Ueki H. Koebner phenomenon in lupus erythematosus with special consideration of clinical findings. Autoimmun Rev. 2005;4: 219-223.

20. Baima B, Sticherling M. Apoptosis in different cutaneous manifestations of lupus erythematosus. Br J Dermatol. 2001;144:958-966.

21. Kuhn A, Beissert S. Photosensitivity in lupus erythematosus Autoimmunity. 2005;38:519-529.

22. Kuhn A, Herrmann M, Kleber S, et al. Accumulation of apoptotic cells in the epidermis of patients with cutaneous lupus erythematosus after ultraviolet irradiation. Arthritis Rheum. 2006;54:939-950.

23. Cardinali C, Caproni M, Fabbri P. The composition of the lupus band test (LBT) on the sun-protected non-lesional (SPNL) skin in patients with cutaneous lupus erythematosus (CLE). Lupus. 1999;8: 755-760.

24. Gaines E, Werth VP. Development of outcome measures for autoimmune dermatoses. Arch Dermatol Res. 2008;300(1):3-9.

25. Albrecht J, Taylor L, Berlin JA, et al. The CLASI (Cutaneous Lupus Erythematosus Disease Area and Severity Index): an outcome instrument for cutaneous lupus erythematosus. J Invest Dermatol. 2005;125:889-894.

26. Bonilla-Martinez ZL, Albrecht J, Troxel AB, et al. The cutaneous lupus erythematosus disease area and severity index: a responsive instrument to measure activity and damage in patients with cutaneous lupus erythematosus. Arch Dermatol. 2008;144:173-180.

27. Kuhn A, Kuehn E, Meuth AM, et al. Development of a Core Set Questionnaire by the European Society of Cutaneous Lupus Erythematosus (EUSCLE). Autoimmun Rev. 2009;8:702-712.

28. Ting WW, Sontheimer RD. Local therapy for cutaneous and systemic lupus erythematosus: practical and theoretical considerations. Lupus. 2001;10:171-184.

29. Lehmann P. Topical treatment of cutaneous lupus erythematosus. In: Kuhn A, Lehmann P, Ruzicka T, editors. Cutaneous lupus erythematosus. Heidelberg: Springer; 2005:337-345.

30. Ermann J, Bermas BL. The biology behind the new therapies for SLE. Int J Clin Pract. 2007;61:2113-2119.

31. Reinhold U, Buttgereit F. High dosage steroid pulse therapy. Is there an indication in dermatology? Hautarzt. 2000;51:738-745.

32. Marmor MF, Carr RE, Easterbrook M, et al. Recommendations on screening for chloroquine and hydroxychloroquine retinopathy: a report by the American Academy of Ophthalmology. Ophthalmology. 2002 ; 109:1377-1382.

33. Ochsendorf FR. Antimalarials. In: Kuhn A, Lehmann P, Ruzicka T, editors. Cutaneous lupus erythematosus. Heidelberg: Springer; 2004. p. 347-372.

34. Costedoat-Chalumeau N, Amoura Z, Hulot JS, et al. Hydroxy-chloroquine in systemic lupus erythematosus. Lancet. 2007;369(9569): 1257-1258.

35. Böhm I, Bruns A, Schupp G, et al. ANCA-positive lupus erythematodes profundus. Successful therapy with low dosage dapsone. Hautarzt. 1998;49:403-407.

36. Böhm I, Wenzel J. FACS monitoring of lymphocyte-subsets in patients with discoid and subacute-cutaneous lupus erythematosus receiving low-dose methotrexate. Scan J Rheumatol. 2002;31:216-220.

37. Schanz S, Ulmer A, Rassner G, et al. Successful treatment of subacute cutaneous lupus erythematosus with mycophenolate mofetil. $\mathrm{Br} J$ Dermatol. 2002;147:174-178.

38. Goyal S, Nousari HC. Treatment of resistant discoid lupus erythematosus of the palms and soles with mycophenolate mofetil. J Am Acad Dermatol. 2001;45:142-144.

39. Tu Y, Peng X, Wang L, et al; MMF in Induction Therapy for Active Lupus Nephritis in Mainland China Study Group. A prospective multicentre study of mycophenolate mofetil combined with prednisolone as induction therapy in 213 patients with active lupus nephritis. Lupus. 2008; 17:622-629. 
40. Boehncke WH, Ochsendorf F, Paeslack I, et al. Decorative cosmetics improve the qualitiy of life in patients with disfiguring skin diseases. Eur J Dermatol. 2002;12:577-580.

41. Luger T, Paul C. Potential new indications of topical calcineurin inhibitors. Dermatology. 2007;215(Suppl 1):45-54.

42. Ho S, Clipstone N, Timmermann L, et al. The mechanism of action of cyclosporin A and FK506. Clin Immunol Immunopathol. 1996;80: S40-S45.

43. Wollina U, Hansel G. The use of topical calcineurin inhibitors in lupus erythematosus: an overview. J Eur Acad Dermatol Venereol. 2008; 22:1-6.

44. Gupta AK, Chow M. Pimecrolimus: a review. J Eur Acad Dermatol Venereol. 2003;17:493-503.

45. Goto T, Nakagawa H. Development of tacrolimus ointment. In: Ruzicka T, Reitamo S, editors. Tacrolimus Ointment. A topical immunomodulator for atopic dermatitis. Heidelberg: Springer; 2004: 81-98.

46. Wollenberg A, Reitamo S, Atzori F, et al. Proactive treatment of atopic dermatitis in adults with $0.1 \%$ tacrolimus ointment. Allergy. 2008;63:742-750

47. Woo DK, James WD. Topical tacrolimus: a review of its uses in dermatology. Dermatitis. 2005;16:6-21.

48. De Prost Y. Clinical experience in children. In: Ruzicka T, Reitamo S, editors. Tacrolimus Ointment. A topical immunomodulator for atopic dermatitis. Heidelberg: Springer; 2004. p. 161-183.

49. Reitamo S. Clinical experience in adults. In: Ruzicka T, Reitamo S, editors. Tacrolimus Ointment. A topical immunomodulator for atopic dermatitis. Heidelberg: Springer; 2004. p. 129-160.

50. Ring J, Abraham A, de Cuyper C, et al. Control of atopic eczema with pimecrolimus cream $1 \%$ under daily practice conditions: results of a $>2000$ patient study. J Eur Acad Dermatol Venereol. 2008;22: 195-203.

51. Dissemond J, Goos M, Wagner SN. Pimecrolimus (SDZ ASM 981). Current state of research. Dtsch Med Wochenschr. 2002;127: 1199-1203.

52. Hoetzenecker W, Ecker R, Kopp T, et al. Pimecrolimus leads to an apoptosis-induced depletion of $\mathrm{T}$ cells but not Langerhans cells in patients with atopic dermatitis. J Allergy Clin Immunol. 2005;115: 1276-1283.

53. Hoetzenecker W, Meingassner JG, Ecker R, et al. Corticosteroids but not pimecrolimus affect viability, maturation and immune function of murine epidermal Langerhans cells. J Invest Dermatol. 2004;122: 673-684.

54. Meingassner JG, Kowalsky E, Schwendinger H, et al. Pimecrolimus does not affect Langerhans cells in murine epidermis. Br J Dermatol. 2003;149:853-857.

55. Queille-Roussel C, Paul C, Duteil L, et al. The new topical ascomycin derivative SDZ ASM 981 does not induce skin atrophy when applied to normal skin for 4 weeks: a randomized, double-blind controlled study. Br J Dermatol. 2001;144:507-513.

56. Draelos ZD. Use of topical corticosteroids and topical calcineurin inhibitors for the treatment of atopic dermatitis in thin and sensitive skin areas. Curr Med Res Opin. 2008;24:985-994.

57. Billich A, Aschauer H, Aszodi A, et al. Percutaneous absorption of drugs used in atopic eczema: pimecrolimus permeates less through skin than corticosteroids and tacrolimus. Int J Pharm. 2004;269: 29-35.

58. Wooltorton E. Eczema drugs tacrolimus (Protopic) and pimecrolimus (Elidel): cancer concerns. CMAJ. 2005;172:1179-1180.

59. Sárdy M, Ruzicka T, Kuhn A. Topical calcineurin inhibitors in cutaneous lupus erythematosus. Arch Dermatol Res. 2009;301:93-98.

60. Walker SL, Kirby B, Chalmers RJ. The effect of topical tacrolimus on severe recalcitrant chronic discoid lupus erythematosus. Br J Dermatol. 2002;147:405-406.

61. Yoshimasu T, Ohtani T, Sakamoto T, et al. Topical FK506 (tacrolimus) therapy for facial erythematous lesions of cutaneous lupus erythematosus and dermatomyositis. Eur J Dermatol. 2002;12:50-52.
62. Böhm M, Gaubitz M, Luger TA, et al. Topical tacrolimus as a therapeutic adjunct in patients with cutaneous lupus erythematosus. A report of three cases. Dermatology. 2003;207:381-385.

63. Bacman D, Tanbajewa A, Megahed M, et al. Topical treatment with tacrolimus in lupus erythematosus tumidus. Hautarzt. 2003;54: 977-979.

64. Kanekura T, Yoshii N, Terasaki K, et al. Efficacy of topical tacrolimus for treating the malar rash of systemic lupus erythematosus. Br J Dermatol. 2003;148:353-356.

65. De la Rosa Carrillo D, Christensen OB. Treatment of chronic discoid lupus erythematosus with topical tacrolimus. Acta Derm Venereol. 2004;84(3):233-234.

66. Drüke A, Gambichler T, Altmeyer P, et al. 0.1\% Tacrolimus ointment in a patient with subacute cutaneous lupus erythematosus. J Dermatolog Treat. 2004;15:63-64.

67. Lampropoulos CE, Sangle S, Harrison P, et al. Topical tacrolimus therapy of resistant cutaneous lesions in lupus erythematosus: a possible alternative. Rheumatology. 2004;43:1383-1385.

68. Meller S, Bruch-Gerharz D, Ruzicka T, et al. Topische Behandlung des subakut-kutanen Lupus erythematodes mit Tacrolimus. Hautarzt. 2005;56:368-369.

69. Heffernan MP, Nelson MM, Smith DI, et al. 0.1\% tacrolimus ointment in the treatment of discoid lupus erythematosus. Arch Dermatol. 2005; 141:1170-1171

70. Sugano M, Shintani Y, Kobayashi K, et al. Successful treatment with topical tacrolimus in four cases of discoid lupus erythematosus. J Dermatol. 2006;33:887-891.

71. Von Pelchrzim R, Schmook T, Friedrich M, et al. Efficacy of topical tacrolimus in the treatment of various cutaneous manifestations of lupus erythematosus. Int J Dermatol. 2006;45:84-85.

72. Tzung TY, Liu YS, Chang HW. Tacrolimus vs clobetasol propionate in the treatment of facial cutaneous lupus erythematosus: a randomized, double-blind, bilateral comparison study. Br J Dermatol. 2007; 156:191-192.

73. Cooper RM, Butler DF, Ghali F, et al. Periorbital cutaneous neonatal lupus. Skinmed. 2007;6(3):145-146.

74. Madan V, August PJ, Chalmers RJ. Efficacy of topical tacrolimus $0.3 \%$ in clobetasol propionate $0.05 \%$ ointment in therapy-resistant cutaneous lupus erythematosus: a cohort study. Clin Exp Dermatol. 2010;35:27-30

75. Kawachi Y, Taguchi S, Fujisawa Y, Furuta J, Nakamura Y, Ishii Y, Otsuka F. Linear Childhood Discoid Lupus Erythematosus Following the Lines of Blaschko: Successfully Treated with Topical Tacrolimus. Pediatr Dermatol. 2010 Sep 1. [Epub ahead of print]

76. Han YW, Kim HO, Park SH, Park YM. Four cases of facial discoid lupus erythematosus successfully treated with topical pimecrolimus or tacrolimus. Ann Dermatol. 2010;22:307-311.

77. Zabawski E. Treatment of cutaneous lupus with Elidel. Dermatol Online J. 2002;8(2):25.

78. Kreuter A, Gambichler T, Breuckmann F, et al. Pimecrolimus 1\% cream for cutaneous lupus erythematosus. J Am Acad Dermatol. 2004; $51: 407-410$

79. Tlacuilo-Parra A, Guevara-Gutiérrez E, Gutiérrez-Murillo F, et al. Pimecrolimus $1 \%$ cream for the treatment of discoid lupus erythematosus. Rheumatology. 2005;44:1564-1568.

80. Sticherling M, Gelbrich G, Rogalski C. Topical pimecrolimus for cutaneous lupus erythematosus - results of a double-blind, placebo controlled study. J Deutsch Dermatol Ges. 2007;5:S188-S1889.

81. Barikbin B, Givrad S, Yousefi M, et al. Pimecrolimus $1 \%$ cream versus betamethasone 17 -valerate $0.1 \%$ cream in the treatment of facial discoid lupus erythematosus: a double-blind, randomized pilot study. Clin Exp Dermatol. 2009;34:776-780.

82. Dé Tran QH, Guay E, Chartier S, Tousignant J. Tacrolimus in dermatology. J Cutan Med Surg. 2001;5:329-335.

83. Graf J, Webb A, Davis J. The use of topical tacrolimus (FK506/Protopic) in cutaneous manifestations of autoimmune diseases. J Clin Rheumatol. 2003;9:310-315. 
84. Gisondi P, Ellis CN, Girolomoni G. Pimecrolimus in dermatology: atopic dermatitis and beyond. Int J Clin Pract. 2005;59:969-974.

85. Lin AN. Innovative use of topical calcineurin inhibitors. Dermatol Clin. 2010;28:535-545.

86. Tzellos TG, Kouvelas D. Topical tacrolimus and pimecrolimus in the treatment of cutaneous lupus erythematosus: an evidence-based evaluation. Eur J Clin Pharmacol. 2008;64:337-341.

87. Merrill JT. Topical tacrolimus and pimecrolimus for cutaneous lupus. Curr Rheumatol Rep. 2008;10:263-264.

88. Jessop S, Whitelaw DA, Delamere FM. Drugs for discoid lupus erythematosus. Cochrane Database Syst Rev. 2009 Oct 7;(4):CD002954.
89. Breneman D, Fleischer AB Jr, Abramovits W, et al. Intermittent therapy for flare prevention and long-term disease control in stabilized atopic dermatitis: a randomized comparison of 3-times-weekly applications of tacrolimus ointment versus vehicle. J Am Acad Dermatol. 2008; 58:990-999.

90. Ring J, Möhrenschlager M, Henkel V. The US FDA ‘black box' warning for topical calcineurin inhibitors: an ongoing controversy. Drug Saf. 2008;31:185-198.

\section{Publish your work in this journal}

Biologics: Targets \& Therapy is an international, peer-reviewed journal focusing on the patho-physiological rationale for and clinical application of Biologic agents in the management of autoimmune diseases, cancers or other pathologies where a molecular target can be identified. This journal is indexed on PubMed Central, CAS, EMBase, Scopus

\section{Dovepress}

and the Elsevier Bibliographic databases. The manuscript management system is completely online and includes a very quick and fair peerreview system, which is all easy to use. Visit http://www.dovepress. com/testimonials.php to read real quotes from published authors. 